\title{
A Virtual Reality Game (The Secret Trail of Moon) for Treating Attention-Deficit/Hyperactivity Disorder: Development and Usability Study
}

Maria Rodrigo-Yanguas ${ }^{1,2^{*}}$, BSc; Marina Martin-Moratinos ${ }^{1,2^{*}}$, BSc; Angela Menendez-Garcia ${ }^{1}$, BSc; Carlos Gonzalez-Tardon $^{3}$, BSc, PhD; Ana Royuela ${ }^{4}, \mathrm{PhD}$; Hilario Blasco-Fontecilla ${ }^{1,2,5,}, \mathrm{MD}, \mathrm{PhD}$

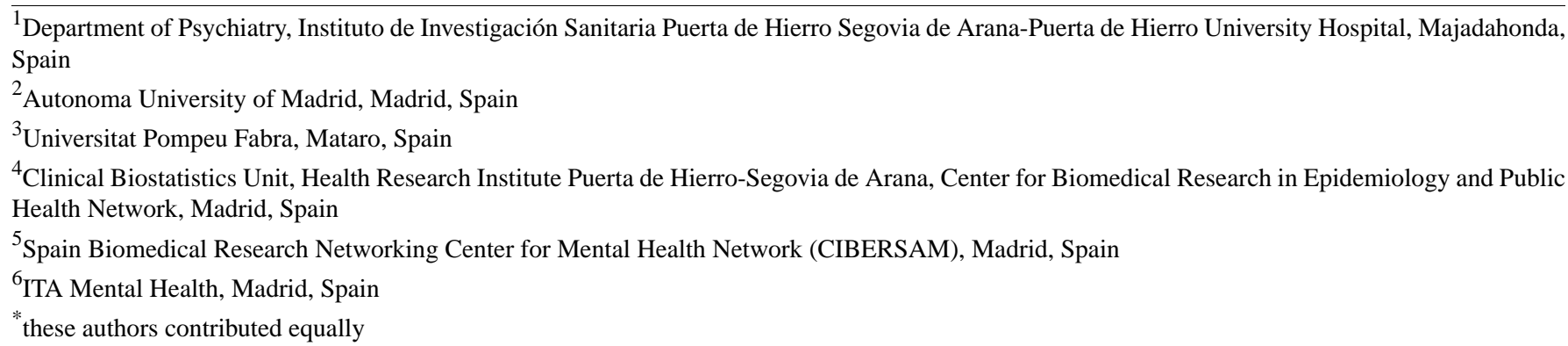

\section{Corresponding Author:}

Hilario Blasco-Fontecilla, MD, PhD

Department of Psychiatry

Instituto de Investigación Sanitaria Puerta de Hierro Segovia de Arana-Puerta de Hierro University Hospital

Avenida, Manuel de Falla 1

Majadahonda, 28222

Spain

Phone: 34655214857

Email: $\underline{\text { hmblasco@yahoo.es }}$

\section{Abstract}

Background: Attention-deficit/hyperactivity disorder (ADHD) affects between $4 \%$ and $8 \%$ of children worldwide. The treatment of choice is multimodal treatment. Multimodal interventions for ADHD may be improved by incorporating new treatments, such as treatment via serious video games. The Secret Trail of Moon (TSTM) is a virtual reality serious video game that was designed for cognitive training related to core ADHD symptoms and executive dysfunction.

Objective: We aimed to describe the development and usability of TSTM.

Methods: The usability study included 37 children and adolescents who tested TSTM during the early usability stage (preinclusion) of a randomized controlled clinical trial for testing the effectiveness of TSTM. Chi-square tests were performed to compare patients with ADHD (ADHD combined subtype vs inattentive subtype) and to compare frequent and infrequent video game players in the second study. We used SPSS version 20 for Macintosh (IBM Corporation).

Results: A total of 31/37 (86\%) and 30/37 (83\%) of participants liked playing TSTM and wanted to continue playing TSTM, respectively. Further, 5/37 (14\%) of participants reported that they experienced either perceived dizziness or virtual reality motion sickness. We found no statistically significant differences after comparing the ADHD combined subtype to the inattentive subtype and frequent video game players to infrequent video game players.

Conclusions: Serious video games, such as TSTM, may complement the current multimodal approach for treating ADHD.

Trial Registration: ClinicalTrials.gov NCT04355065; https://clinicaltrials.gov/ct2/show/NCT04355065

(JMIR Serious Games 2021;9(3):e26824) doi: 10.2196/26824

\section{KEYWORDS}

attention-deficit/hyperactivity disorder; chess; virtual reality; serious video game; psychotherapy; cognitive training; usability; new technologies; transfer; randomized controlled trial 


\section{Introduction}

\section{Background}

Attention-deficit/hyperactivity disorder (ADHD) is the most common neurodevelopmental disorder of childhood and adolescence; it affects $4 \%$ to $8 \%$ of children worldwide [1]. Apart from the core ADHD symptoms (inattention, hyperactivity, and impulsivity), patients with ADHD frequently present with poor social skills, problems in planning, and the inability to complete tasks on time [2]. The prognosis of ADHD is complicated by comorbidities, and impairments may intensify during adolescence or adulthood [2,3]. The treatment of ADHD is multimodal and can include the use of medication, psychoeducation, and psychological intervention [4]. Unfortunately, the current multimodal approach for ADHD treatment has some shortcomings [5]. For instance, motivation is critical for people with ADHD, and they sometimes lack the motivation to engage in treatment [6]. Furthermore, psychotherapies can be expensive [7] and have high rates of treatment discontinuation [8,9]. As such, the incorporation of new treatments that promote high levels of motivation may be a good strategy for improving ADHD outcomes and prognoses.

Some recent proposals include the use of board games, such as chess [10]; neurofeedback [11,12]; virtual reality (VR) [13]; or serious video games [14]. All of these new approaches have the potential to keep people with ADHD motivated and engaged during therapy. Indeed, serious video games can be very stimulating and provide immediate reinforcement [15]. In addition, they present some advantages, such as [15] (1) the precise control of variables, (2) easy data collection that allows for the evaluation of a patient's progress, (3) the provision of immediate feedback to the user, and (4) a more attractive presentation (ie, a video game format). It is not surprising that various serious video games have recently been developed to treat ADHD [15-17]. However, it is also important to mention some disadvantages. For instance, a major problem for people with ADHD is their vulnerability to some addictions, particularly the addiction to video games. Children and adolescents with ADHD are more likely to present with internet gaming disorder [18]. Thus, when developing a serious video game for treating $\mathrm{ADHD}$, it is necessary to find a balance between obtaining a good level of user satisfaction and avoiding increasing the risk of becoming addicted to this video game. Independent of the factors that influence addiction in the design of a serious video game, researchers can control the patients who enter into a study, since addiction is linked with adverse childhood experiences
$[19,20]$ and game addiction is specifically linked with ADHD severity level [21].

Another problem is the lack of evidence regarding the transfer of improvements and benefits. In other words, it is not known whether improvements in video game performance would translate into improvements in other cognitive tasks in a subject's daily life. For instance, regular chess use has been demonstrated to transfer benefits to the educational domain (eg, by improving mathematics performance) [22]. However, evidence about a potential transfer to the health domain is lacking. The challenge of cognitive training and transfer was addressed by Rabipour and Raz [23]. These authors recommended the potential use of brain training to ameliorate the undesired symptoms of ADHD. They also raised the question of the transfer "of practiced skills to other untrained cognitive domains." Furthermore, high-quality evidence that supports the massive use of video games to treat ADHD is scarce. Indeed, there is just 1 video game that has recently been approved by the Food and Drug Administration for decreasing the severity of ADHD [24].

The development of any serious video game requires a series of stages $[15,25,26]$ - (1) defining the learning goals (theoretical background and initial design); (2) creating prototypes (proof of concept); and (3) testing usability and clinical effectiveness (in this order). A recent example is Plan-It Commander-a serious game that was developed for children with ADHD [15]. They initially defined the learning goals and created a prototype to test the game's usability and user satisfaction [15]. Afterward, they tested its clinical effectiveness in a randomized controlled trial [16]. They found that girls as well as boys with higher levels of conduct problems were the subgroups that benefited the most from playing the video game [27].

In addition to the development stages reported above, we present the third step (usability) of the development of The Secret Trail of Moon (TSTM) - a serious video game that was specifically created to train patients with ADHD and increase various cognitive abilities. This usability study allowed us to (1) obtain initial feedback from patients with ADHD; (2) detect bugs and integrate improvements; and (3) confirm that the use of our VR video game was attractive, was intuitive, and did not generate severe adverse effects in users.

\section{Deconstructing TSTM: Theoretical Background, Design, Development, and Description}

\section{Development Stages}

The development stages of TSTM are shown in Figure 1. 
Figure 1. Design and development stages of the user-centered design study.

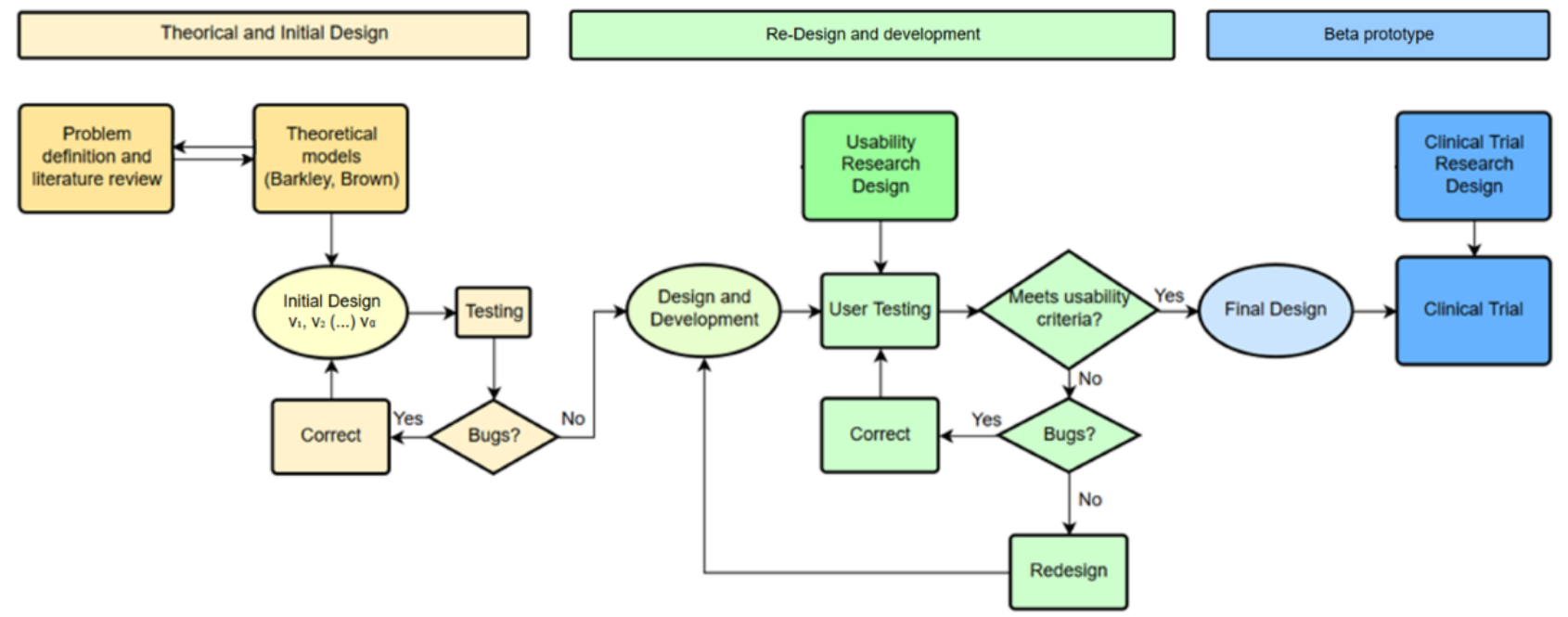

\section{Theoretical Background}

Information about the first stage of TSTM development can be found elsewhere [28]. The main characteristics of TSTM are summarized in Table 1. These characteristics were influenced by work that was conducted by others [29].

TSTM is the result of interdisciplinary collaboration among health care professionals, researchers, serious video game consultants, and a single educational and therapeutic game development company. This collaboration made it possible to integrate several theoretical models of ADHD with clinical experience, the use of chess and VR by patients with ADHD, and other playful elements of video games that increase players' motivation for engaging in therapy [30].

TSTM is theoretically driven by (1) both the Barkley [2] and Brown [21] models of ADHD and executive dysfunction and (2) our personal clinical experience of using chess with patients with ADHD [10]. The original Barkley model was based on the work of other researchers, such as Bronowski and Fuster [31,32]. This model focuses mainly on the hyperactive-impulsive ADHD subtype (type 2). The primary premise of the Barkley ADHD model is a deficit in behavioral inhibition. This deficit in inhibition is related to problems in the following four executive neuropsychological functions: (1) working (nonverbal) memory; (2) the self-regulation of affect-motivation and arousal; (3) the internalization of speech (verbal working memory); and (4) reconstitution, which is understood as the ability to manipulate verbal and nonverbal mental representations (behavioral analysis and synthesis) [2].

The Brown ADHD model postulates that the core deficit depends on executive dysfunction. In the Brown model, ADHD is considered to involve 6 major deficits in activation, focus, effort (motivation), emotion, memory, and action. In the Brown model, similar to the Barkley model, executive dysfunction is core to ADHD. However, both models have some differences [21]. The Barkley model focuses on the combined type of ADHD and emphasizes the relevance of behavioral inhibition. In contrast, in the Brown model, behavioral inhibition is just 1 of the 6 defective executive functions $[2,21]$.

The TSTM prototype that was used in this usability study had 5 minigames; each minigame targeted specific cognitive abilities (Table 2) and particularly focused on inhibitory control, selective attention, cognitive flexibility, or processing speed [2,33]. The minigames were embedded into a VR forest context in order to provide a more immersive and motivating experience [28]. Furthermore, as stressed by Rabipour and Raz [23], "regular interaction with nature appears to facilitate improvements in cognitive function and behavioral control." A minigame was defined as "a small, isolated game within the larger game environment that integrates unique game elements offering tools to improve strategic behavior" [15].

After an initial design of TSTM was produced, we iteratively tested modified versions in order to detect and correct all bugs [34]. Furthermore, we integrated all suggestions that were made by different users who tested the initial version. Accordingly, we included several modifications that allowed us to create a redesigned video game (redesign stage) [34]. We gathered further information on usability criteria, such as effectiveness, efficiency, user satisfaction, and the adverse consequences of use, and fixed some extra bugs. Thanks to this, we constructed the first functional prototype.

In conclusion, TSTM is a serious video game that is defined as either a game that was designed for a primary purpose other than entertainment [35] or a "computer-based [game] designed for training purposes" [36]. We also used gamification [37,38] to introduce chess and to teach the basic rules of chess to participants who did not know how to play the game. 
Table 1. Brief description of The Secret Trail of Moon (TSTM) characteristics (based on Baranowski [30]).

\begin{tabular}{ll}
\hline TSTM Characteristics & Description
\end{tabular}

\section{General characteristics}

Health topics

Targeted age groups

Other targeted group characteristics

Short description of the game idea

Target players

Guiding knowledge, behavior change theory models, or conceptual frameworks

Intended health behavior changes

Knowledge elements to be learned

Behavior change procedures or therapeutic procedures used

Clinical or parental support needed

Data are shared with parent or clinician

Type of game

Story

Synopsis

How the story relates to targeted behavior change

\section{Game components}

Player's game goals and objectives

Rules

Game mechanics

Procedures to generalize or transfer outside of the game

\section{Virtual environment}

Setting

\section{Avatar}

Characteristics
Abilities
Game platform(s) needed to play the game
Sensors used

Estimated play time
Attention-deficit/hyperactivity disorder (ADHD) and attention-deficit disorder (ADD)

Individuals aged $12-22$ years

Exclusion criteria: epilepsy and dizziness (severe)

$A \mathrm{VR}^{\mathrm{a}}$ serious video game aimed at cognitive training related to various cognitive abilities and core ADHD symptoms

Individual

The Thomas Brown model of executive functions and the Barkley Behavioral Inhibition Model

Improvements in attention-deficit/hyperactivity disorder symptomatology

Cognitive abilities

Feedback and monitoring, the achievement of goals and planning, the shaping of knowledge, repetition, natural consequences, rewards, and regulation and identity techniques

Clinical support

Yes

Adventure and puzzles

A kid appears suddenly in a cave and is greeted by a curious black fox that talks. While traveling together, they eventually meet a scurrying raccoon, and together they form the $\mathrm{MOON}^{\mathrm{b}}$ team. Through their adventures in the woods, they will learn about an impending war between two animal factions that want to fill the power vacuum that the King of the Forest-Cernuous-left when he vanished. Wanting to unite all animals again, they set out on a quest to find Cernuous and put an end to the war that threatens the coexistence and nature of the forest itself.

This is a VR adventure experience that is augmented by some specifically designed mechanics. The main goal of the game is to find the King of the Forest throughout several chapters by following the main storyline of the MOON team while resolving problems (game mechanics) in the forest.

Cognitive training by using game mechanics

Restricted cognitive training (25 minutes per session and per day) and exploring the forest (10 minutes)

Smasher (minigame for sustained attention and impulse control), Enigma (minigame for working memory), Kuburi (minigame for visuospatial ability), Teka Teki (minigame for planning), and chess (minigame for reasoning)

Help enhance metacognitive thinking strategies through game play, clinical support, and VR immersion

In the forest, there are ruins of ancient civilizations that praised chess.

The MOON ${ }^{\mathrm{b}}$ team consists of the player as well as Movi (raccoon) and One (fox), who will help and accompany the player throughout the game.

Characters will help regulate behavior and be a role model for the player

PlayStation 4 VR (Sony Group Corporation)

PlayStation 4 VR sensor (Sony Group Corporation)

6-8 hours

${ }^{\mathrm{a}} \mathrm{VR}$ : virtual reality.

${ }^{\mathrm{b}}$ MOON: Movi and One. 
Table 2. Description of each minigame.

\begin{tabular}{|c|c|c|}
\hline Minigame & Target & Description \\
\hline Smasher & $\begin{array}{l}\text { - Sustained attention (based on the Brown model of at- } \\
\text { tention-deficit/hyperactivity disorder) } \\
\text { - Inhibitory control }\end{array}$ & $\begin{array}{l}\text { Within this minigame, participants must break a rock that } \\
\text { is blocking their way by following the appropriate set of } \\
\text { chess pieces. }\end{array}$ \\
\hline
\end{tabular}
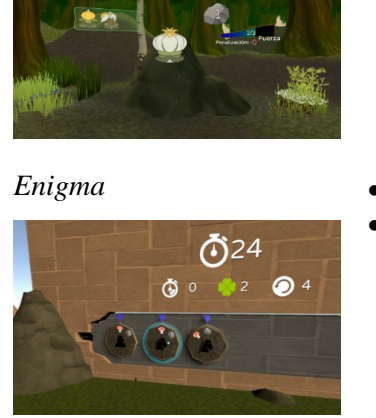

- Working memory

- Cognitive flexibility
Participants must memorize the associations among different elements. Afterward, they must match the association as quickly as possible.

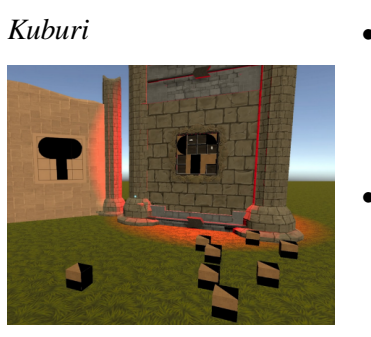

Teka Teki

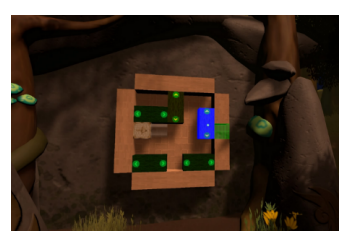

Chess

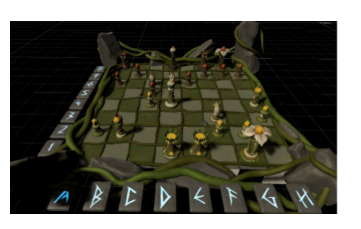

- Visuospatial ability

- According to the classic Baddeley model (1992), the visuospatial agenda is part of working memory.

- Cognitive flexibility
Participants must create a drawing by using the face and orienting some cubes.
Participants can obtain a key if they can help the fox follow her path to the lock. However, the path is obstructed by different blocks. The number of possible movements will decrease, thus increasing the difficulty.

\section{Study 1 (Market Study)}

\section{Methods}

\section{Sample and Procedure}

The objective of our market study was to determine whether brain training via a serious video game, such as TSTM, would be of interest to mental health and education professionals. A survey that included the characteristics of TSTM and general questions about the game was designed. We used the Google Forms platform to disseminate Spanish and English versions of the survey through professional networks [39]. A total of 57 people responded, but 1 person was excluded, as he was neither a health worker or an education worker (he was a programmer).
The local Committee of Medical Ethics did not require official review for study 1.

\section{Statistical Analyses}

We only analyzed the percentage of responses. No statistical test was needed.

\section{Results}

The survey was completed by 56 mental health (mostly psychologists and neuropsychologists) and education professionals (teachers, pedagogues, counselors, etc), of which $71 \%(40 / 56)$ either treat and educate or have treated and educated people with ADHD. A total of $91 \%$ (51/56) and $87 \%$ (49/56) of the professionals thought that a serious video game such as TSTM could be useful and stated that they would use it as a therapy and educational tool, respectively (Table 3 ). 
Table 3. Results of our market survey study (study 1).

\begin{tabular}{ll}
\hline Factors and questions & Yes, n (\%) \\
\hline $\begin{array}{l}\text { Potential use: "Do you think a scientifically validated tool with these features which can help you in ADHD treatment could } \\
\text { be useful?" }\end{array}$ & 51 (91) \\
Practical use: "Would you use it in therapy session?" & $49(87)$ \\
Profile adaptation: "Do you think it is relevant to be able to adapt the tool to various ADHD profiles? (Inattentive, hyperactive...)" & $54(96)$ \\
Adaptive settings: "Would you like to be able to modify variables according your patient needs? (Distracters, number of elements & 55 (98) \\
to memorize...)" &
\end{tabular}

\section{Discussion}

Responses about the characteristics of TSTM helped us to prioritize some development goals Some of the recommendations that were made were in line with literature that stressed the relevance of using attractive graphics or minigame mechanics with an increasing difficulty curve $[15,40]$.

\section{Study 2 (Usability Study)}

\section{Methods}

\section{Sample and Procedure}

The second study included the first 40 consecutive patients with ADHD who were offered inclusion into a randomized controlled clinical trial (RCT) for testing the effectiveness of either TSTM or web-based chess [41]. This RCT study was a prospective, unicentric, randomized nonequality trial for patients with ADHD. All participants underwent drug titration (up to the optimum drug dose) and were determined to be clinically stable before the baseline evaluation. Patients were randomized into the following three groups: TSTM group (cognitive training via TSTM), the therapeutic chess group (web-based cognitive training via chess), and the control group (patients were called every week, but no cognitive intervention was used) [42]. The allocation ratio was equal in all 3 groups (35 participants per branch).

The patients included in this early usability stage tested the initial version of TSTM between December 6, 2019, and February 22, 2020, at preinclusion. In order to provide all available information before entering into the RCT, patients were offered the opportunity to test TSTM at preinclusion. Of the first 40 patients, 3 were excluded from the statistical analyses either because they did not complete the test or because the data provided were incomplete. The remaining 37 patients tested TSTM and eventually entered the study. However, not all patients were allocated to TSTM group, as randomization took place during the inclusion visit (day 0 ), and the data presented in this paper were recorded at preinclusion.
The inclusion criteria were (1) an age of 12-22 years, (2) competency in the Spanish language, and (3) written informed consent. The exclusion criterion was epilepsy, since the use of VR is not recommended for individuals with epilepsy, as per the official recommendations of PlayStation VR [43]. Ethical approval was obtained from the local Committee of Medical Ethics at Puerta de Hierro University Hospital - Majadahonda (Madrid, Spain; research project code: PI 187/19; approved on December 1, 2019). Written informed consent was obtained from participants and at least 1 parent.

The materials used for this study included the video game itself (TSTM), VR glasses, PlayStation 4 controllers (Sony Group Corporation), test kit consoles, monitoring screens, and headphones. The VR software runs on a PlayStation 4 (Sony Group Corporation) test device, which allows for the tracking of movement through the camera (eg, position, head movement, speed, etc).

Demographics, previous VR experience, and vision problems were noted by using an ad hoc questionnaire. The testing time was always monitored by a professional looking through a screen (Figure 2).

Initially, participants attended a single session in which they tested the TSTM experience. Patients with ADHD were given the opportunity to test a single minigame. After passing the tutorial of the minigame to be tested, a higher level of difficulty was tested. Patients could test each minigame for as long as they liked (ie, only for the duration of that session). After testing a single minigame, patients rated their opinion about the minigame by using an ad hoc questionnaire, which included (1) 5 general questions about the TSTM experience and (2) 2 questions about possible adverse effects. Based on previous studies [44-46], we included information about perceived dizziness and motion sickness, which were rated by using a 3-point Likert scale and 2 questions about patients' feelings before and after testing TSTM. Standard questionnaires were used as a reference [47] by adapting them to the characteristics of our video game and using language adapted for children. We arbitrarily determined that a user satisfaction rate of $75 \%$ would indicate a good level of acceptance by users. 
Figure 2. Picture of the principal investigator (HBF) facing The Secret Trail of Moon.

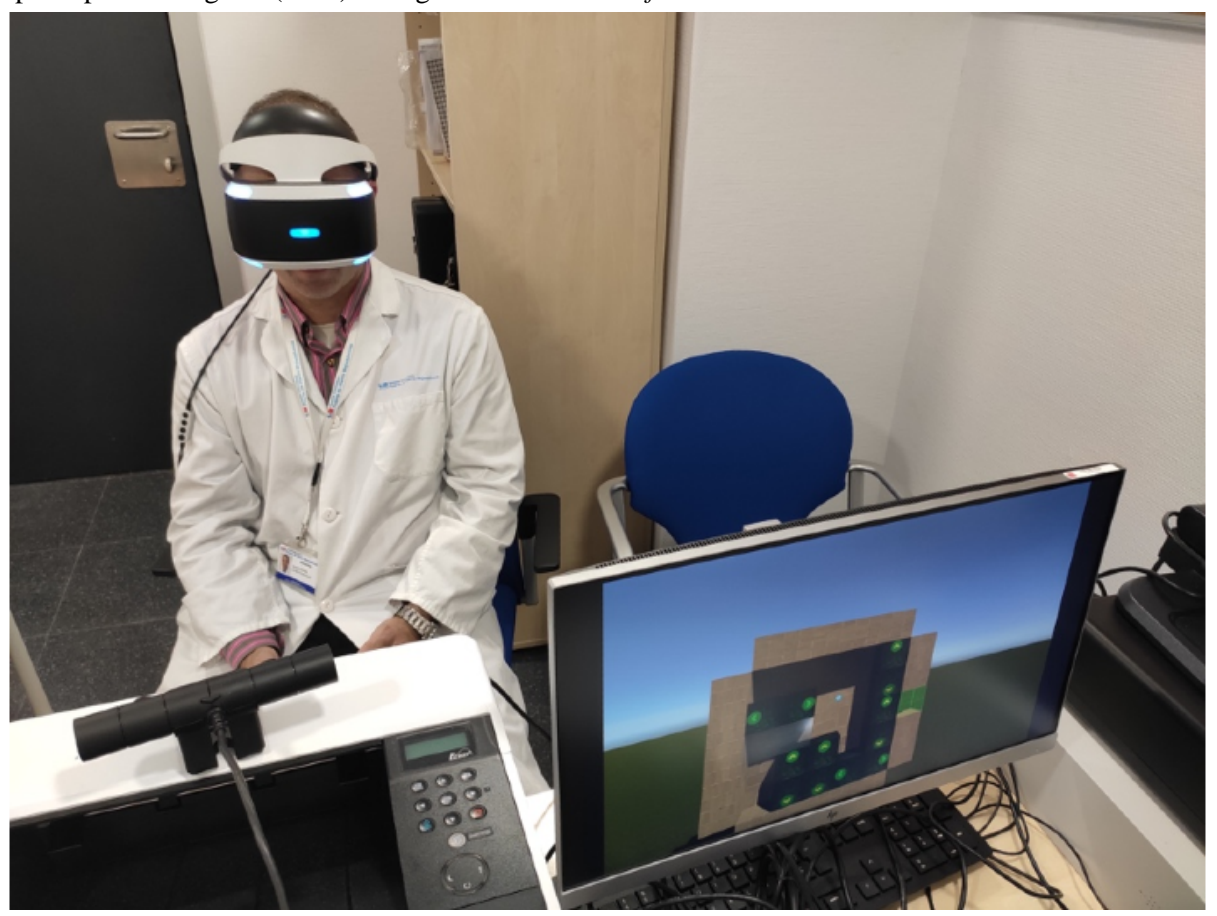

\section{Statistical Analyses}

Participants were divided into the ADHD combined and inattentive subtypes because some authors consider these subtypes to be different disorders and believe that they should be treated separately. Thus, we feared that the different subtypes of ADHD would impact our usability measures. A descriptive analysis was performed by using the mean proportions (\%) of participants' ratings for categorical variables and means and SDs for numerical variables. Chi-square tests were performed to compare patients with ADHD (ADHD combined subtype vs inattentive subtype) and to compare frequent and infrequent video game players. We used SPSS version 20 for Macintosh (IBM Corporation).

Results

\section{Sociodemographic Characteristics}

Table 4 displays the basic demographic and clinical characteristics of participants. The testing time for the video game lasted between 10 and 40 minutes (mean 21.31 minutes, SD 6.77 minutes). Most participants were male (25/37, 68\%), were right-handed $(29 / 37,78 \%)$, never repeated a school year $(26 / 37,70 \%)$, and were diagnosed with at least 1 comorbid mental disorder $(28 / 37,76 \%)$. Further, $38 \%$ (14/37) of participants wore glasses, 59\% (22/37) had previously used VR, and $70 \%(26 / 37)$ played video games regularly. We found no statistically significant differences between the combined and inattentive subtypes of ADHD. 
Table 4. Demographics of the attention-deficit/hyperactivity disorder (ADHD) and attention-deficit disorder (ADD) subtypes (N=37).

\begin{tabular}{|c|c|c|c|c|}
\hline Demographic characteristics & All subtypes $(\mathrm{N}=37)$ & $\begin{array}{l}\text { Participants with ADHD } \\
\text { (combined subtype; } 21 / 37 \text {, } \\
57 \% \text { ) }\end{array}$ & $\begin{array}{l}\text { Participants with ADD } \\
\text { (inattentive subtype; 16/37, } \\
43 \% \text { ) }\end{array}$ & $P$ value \\
\hline Age (years), mean $(\mathrm{SD})^{\mathrm{a}}$ & $13.78(2.28)$ & $13.38(2.156)$ & $14.31(2.387)$ & .222 \\
\hline Intelligence quotient, mean $(\mathrm{SD})^{\mathrm{b}}$ & $106.42(17.91)$ & $104.07(16.69)$ & $108.76(19.44)$ & .525 \\
\hline \multicolumn{5}{|l|}{ Gender, n (\%) } \\
\hline Male & $25(68)$ & $14(67)$ & $11(69)$ & 1 \\
\hline Repeated at least 1 school year, $\mathrm{n}(\%)$ & $11(30)$ & $7(33)$ & $4(25)$ & .723 \\
\hline Handedness, n (\%) & & & & .595 \\
\hline Right-handed participants & $29(78)$ & $16(76)$ & $13(81)$ & \\
\hline Left-handed participants & $1(3)$ & $1(5)$ & $0(0)$ & \\
\hline Ambidextrous participants & $5(14)$ & $2(9)$ & $3(19)$ & \\
\hline Comorbidity with at least 1 mental disorder (yes), $\mathrm{n}(\%)$ & $28(76)$ & $16(76)$ & $12(75)$ & 1 \\
\hline Wears glasses, $\mathrm{n}(\%)$ & $14(38)$ & $9(43)$ & $5(31)$ & .432 \\
\hline Previous use of virtual reality, n (\%) & $22(59)$ & $12(57)$ & $10(63)$ & 1 \\
\hline Regularly plays video games, n (\%) & $26(70)$ & $16(76)$ & $10(63)$ & .203 \\
\hline
\end{tabular}

${ }^{\mathrm{a}}$ Data were collected from 37 participants.

${ }^{\mathrm{b}}$ Data were collected from 26 participants.

\section{Usability Results}

Figure 3 displays the proportion of children and adolescents who liked each minigame. All minigames were based on the opinions of the participants, and percentages ranged from $80 \%$ (chess: 4/5) to $100 \%$ (Kuburi: 22/22; Teka Teki: 23/23). With regard to the results for comprehensibility, the ease of play, and the ease of control of the PlayStation 4 controller, all proportions surpassed 60\% (22/36). All minigames were easy to play, and only Teka Teki had an easy-to-play percentage of below $80 \%$ $(22 / 36,61 \%)$. Teka Teki was the only minigame in which the participants pointed out that it was difficult to achieve improvement after repeating the minigame. We found no statistically significant differences after comparing the ADHD combined subtype to the inattentive subtype and frequent video game players to infrequent video game players.

Table 5 displays the percentages of children and adolescents who had positive opinions, which were based on the two highest scores ("much" or "very much"). With regard to the discomfort of VR glasses and motion sickness, we considered any level of discomfort to be a negative opinion, even if it was just "a little bit" of discomfort. Most children and adolescents provided very positive responses to all questions. Furthermore, 5 out of 36 $(13.1 \%)$ children and adolescents reported the discomfort of VR glasses and motion sickness, and just $1(3 \%)$ reported this clearly.

Figure 3. Specific questions about each game's mechanics (Smasher, Kuburi, Enigma, Teka Teki, and chess). The questions were as follows: (1) "Was the minigame fun" (factor: fun), (2) "Did you find it easy to understand the instructions" (factor: comprehensible), (3) "Did you find the minigame easy to play" (factor: easy to play), (4) "Did you find the controller easy to use" (factor: proper control), (5) "Do you understand the game better as the level increases" (factor: improvement after repeating), (6) "Did you think visual graphics were beautiful" (factor: enjoyable graphics), and (7) "Did you find it short" (factor: too short)?

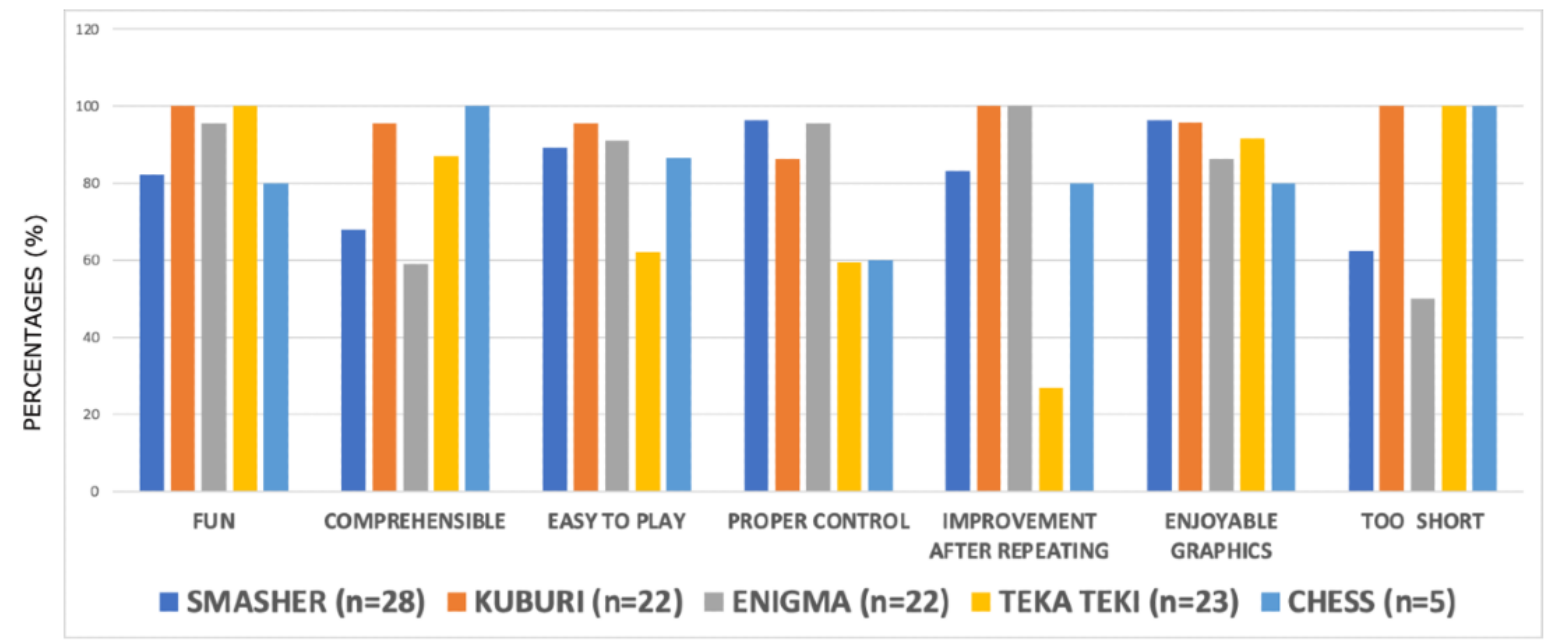


Table 5. The satisfaction of patients with attention-deficit/hyperactivity disorder after testing The Secret Trail of Moon (TSTM).

\begin{tabular}{|c|c|}
\hline Factors and questions (responses) & Positive experience $\left(\mathrm{n}=36^{\mathrm{a}}\right), \mathrm{n}(\%)$ \\
\hline Satisfying experience: "Did you like the experience?" (much or very much) & $31(86)$ \\
\hline Desire to repeat: "Would you repeat it?" (much or very much) & $30(83)$ \\
\hline Enjoyable graphics: "Did you find it beautiful?" (much or very much) & $30(83)$ \\
\hline Enjoyable music and sound: Did you like the music and sound?" (much or very much) & $27(75)$ \\
\hline Easy to understand: "Did you find it easy to understand the game?" (much or very much) & $28(78)$ \\
\hline Perceived dizziness: "Did you feel dizzy when playing the video game?" (much or very much) & $5(14)$ \\
\hline VR motion sickness: "Did you become motion sick while playing the video game?" & $5(14)$ \\
\hline Feelings before testing TSTM: "How do you feel?" (good or very good) & $26(73)$ \\
\hline Feelings after testing TSTM: "How do you feel?" (good or very good) & $36(100)$ \\
\hline
\end{tabular}

${ }^{\mathrm{a}}$ Information regarding satisfaction was not recorded for 1 patient out of the 37 included in the second study.

\section{Discussion}

Our study expands on current knowledge concerning the development of serious video games for treating patients with ADHD [15-17,25-28,33,48]. Before serious video games are incorporated into the multimodal treatment of ADHD, they must demonstrate clinical usefulness and have tolerable side effects $[15,25,26,28]$.

Our results suggest that TSTM was fun, was understandable, was easy to play, was intuitive, was easy to master, used enjoyable graphics, and was of adequate duration for most participants. However, there were some interesting differences between each minigame that may suggest that certain components of TSTM need more improvement. The most enjoyable minigames (Teka Teki and Kuburi) were the most dynamic and interactive minigames. The areas for improvement in Smasher appear to be making it a little bit easier to understand and extending the play time. Kuburi was the minigame with the highest usability ratings across all parameters. Enigma was the minigame that was the most difficult for users to comprehend. Thus, we may have made the graphics too attractive or enhanced minigame mechanics with an increasing difficulty curve $[15,40]$. Teka Teki was the most difficult minigame to play and the only minigame in which participants found it difficult to achieve improvement after repeating the minigame. As such, this minigame may need some improvement, such as using a less stringent difficulty curve and thus preventing a potential decline in initial motivation $[15,40]$. As for chess, we obtained the opinions of just 5 patients. Therefore, there is too little information to extract any meaningful data on the game.

Compared to a similar study, our study yielded better satisfaction percentages than those reported by the users of Plan-It Commander [15]. For instance, compared to the $72 \%$ of participants who reported feeling good or very good before testing Plan-It Commander, 100\% (36/36) of our participants reported feeling good or very good after testing TSTM. Furthermore, our results are comparable to those reported in the Plan-It Commander study with regard to players' motivation to play the game again and their opinions of the game [15]. Finally, a small proportion of participants $(5 / 36,14 \%)$ reported experiencing either perceived dizziness or motion sickness, which was clinically meaningful in just 1 child $(1 / 36,3 \%)$. Wearing glasses was not related to either of the two side effects. Both perceived dizziness and motion sickness are the potential side effects of VR that are the most frequently reported in literature [44-46].

Our usability study presents the following limitations. First, not all of the participants tested the same versions of each minigame during the usability phase, although the changes made were kept at a minimum. We used the preinclusion period of the RCT to fix the bugs detected by participants, and we made some improvements based on their ongoing suggestions in an iterative, continuous way. Thus, the data reported in this paper were the data collected during the preinclusion period. However, after the preinclusion period, all included participants in the RCT eventually tested the same TSTM version. Second, our questionnaire was not validated but was based on questionnaires that were used in similar studies [15]. Finally, we based TSTM development on 2 predominant theoretical models of ADHD. However, there are other ADHD models that integrate cognitive and affective science data and may be interesting to consider when constructing a therapeutic video game for treating ADHD $[30,49]$.

\section{Conclusion and Future Directions}

Serious video games and VR are new technologies that can be used as therapeutic tools for the treatment of mental disorders $[24,50]$. Compared to traditional treatments, serious video games have many advantages [48,50], such as helping individuals maintain their commitment to therapy $[2,13,14]$. Furthermore, VR has already proven its therapeutic utility for some mental disorders [47,51,52], but such evidence for ADHD is limited [53]. Moreover, there is an increasing number of studies that have reported encouraging results about the use of serious video games and gamified versions of different tests for treating and diagnosing ADHD populations, respectively [15-17,54-56]. Thus, in a recent clinical trial that included 857 children with ADHD, the researchers reported that the patients who were randomized to a serious video game (Akili interactive) intervention group improved more than those who were randomized to the digital control intervention group and experienced fewer adverse events [24]. In another study that 
compared a serious game intervention (Plan-It Commander) group to a treatment-as-usual crossover group (the intervention was used as an adjunct treatment for children with ADHD), the 10 -week serious game intervention proved to be a more effective strategy [16]. However, the creation, development, and empirical testing of a serious video game are not easy tasks [29,57]; the game must be proven to be safe, and its use is not easy to implement in real settings.
TSTM - a VR serious video game that was designed for patients with ADHD—was fun, was intuitive, and displayed a favorable profile of side effects that were in line with those reported in literature [44-46]. Additionally, TSTM may have the potential to be used as an add-on cognitive training tool for medically treated patients with ADHD.

\section{Acknowledgments}

We thank all of the children, adolescents, and parents for their participation in this study. The authors thank Lorraine Maw, MA, for her editorial assistance. HBF is the principal investigator of an iPFIS research contract (contract number: IFI16/00039) [58] and coprincipal investigator of an Ministerio de Asuntos Económicos y Trasformación Digital (MINECO) research grant (grant RTI2018-101857-B-I00); is the recipient of (1) a Fundación para la innovación y la prospective en salud en España Grant and (2) an Instituto de investigación sanitaria Puerta de Hierro intensification grant; and is involved in two clinical trials (NEWROFEED study [trial number: NCT02778360]; ESKETSUI2002 study [trial number: NCT03185819]). MRY is the recipient of an iPFIS research contract (contract number: IFI16/00039) [58]. MMM is the recipient of a Centro para el Desarrollo Industrial grant (Fondo Europeo de Desarrollo Regional [FEDER] funded; grant IDI-20180701; file number: 00107278).

\section{Conflicts of Interest}

In the last 24 months, HBF received lecture fees from Shire. He is a member of the Advisory Board of ITA Mental Health [59]. The remaining authors do not have any conflicts of interest regarding the publication of this manuscript.

\section{References}

1. Dulcan M. Practice parameters for the assessment and treatment of children, adolescents, and adults with attention-deficit/hyperactivity disorder. American Academy of Child and Adolescent Psychiatry. J Am Acad Child Adolesc Psychiatry 1997 Oct;36(10 Suppl):85S-121S. [doi: 10.1097/00004583-199710001-00007] [Medline: 9334567]

2. Barkley RA. Attention-Deficit Hyperactivity Disorder: A Handbook for Diagnosis and Treatment (3rd ed.). New York: The Guilford Press; 2006.

3. Kieling R, Rohde LA. ADHD in children and adults: diagnosis and prognosis. Curr Top Behav Neurosci 2012;9:1-16. [doi: 10.1007/7854 2010 115] [Medline: 21499858]

4. Mehta S, Mehta V, Mehta S, Shah D, Motiwala A, Vardhan J, et al. Multimodal behavior program for ADHD incorporating yoga and implemented by high school volunteers: a pilot study. ISRN Pediatr 2011;2011:780745 [FREE Full text] [doi: 10.5402/2011/780745] [Medline: 22389788]

5. Castellanos FX, Lee PP, Sharp W, Jeffries NO, Greenstein DK, Clasen LS, et al. Developmental trajectories of brain volume abnormalities in children and adolescents with attention-deficit/hyperactivity disorder. JAMA 2002 Oct 09;288(14):1740-1748. [doi: 10.1001/jama.288.14.1740] [Medline: 12365958]

6. Sonuga-Barke EJS, Brandeis D, Cortese S, Daley D, Ferrin M, Holtmann M, European ADHD Guidelines Group. Nonpharmacological interventions for ADHD: systematic review and meta-analyses of randomized controlled trials of dietary and psychological treatments. Am J Psychiatry 2013 Mar;170(3):275-289. [doi: 10.1176/appi.ajp.2012.12070991] [Medline: 23360949]

7. Jensen PS, Garcia JA, Glied S, Crowe M, Foster M, Schlander M, et al. Cost-effectiveness of ADHD treatments: findings from the multimodal treatment study of children with ADHD. Am J Psychiatry 2005 Sep;162(9):1628-1636. [doi: 10.1176/appi.ajp.162.9.1628] [Medline: 16135621]

8. Pottegård A, Bjerregaard BK, Kortegaard LS, Zoëga H. Early discontinuation of attention-deficit/hyperactivity disorder drug treatment: a Danish nationwide drug utilization study. Basic Clin Pharmacol Toxicol 2015 Apr 07;116(4):349-353 [FREE Full text] [doi: 10.1111/bcpt.12325] [Medline: 25220739]

9. van den Ban E, Souverein PC, Swaab H, van Engeland H, Egberts TCG, Heerdink ER. Less discontinuation of ADHD drug use since the availability of long-acting ADHD medication in children, adolescents and adults under the age of 45 years in the Netherlands. Atten Defic Hyperact Disord 2010 Dec 30;2(4):213-220 [FREE Full text] [doi: 10.1007/s12402-010-0044-9] [Medline: 21258431]

10. Blasco-Fontecilla H, Gonzalez-Perez M, Garcia-Lopez R, Poza-Cano B, Perez-Moreno MR, de Leon-Martinez V, et al. Efficacy of chess training for the treatment of ADHD: A prospective, open label study. Rev Psiquiatr Salud Ment 2016;9(1):13-21. [doi: 10.1016/j.rpsm.2015.02.003] [Medline: 25911280]

11. Cho BH, Kim S, Shin DI, Lee JH, Lee SM, Kim IY, et al. Neurofeedback training with virtual reality for inattention and impulsiveness. Cyberpsychol Behav 2004 Oct;7(5):519-526. [doi: 10.1089/cpb.2004.7.519] [Medline: 15667046] 
12. Bioulac S, Purper-Ouakil D, Ros T, Blasco-Fontecilla H, Prats M, Mayaud L, et al. Personalized at-home neurofeedback compared with long-acting methylphenidate in an european non-inferiority randomized trial in children with ADHD. BMC Psychiatry 2019 Aug 01;19(1):237 [FREE Full text] [doi: 10.1186/s12888-019-2218-0] [Medline: 31370811$]$

13. Bioulac S, Micoulaud-Franchi J, Maire J, Bouvard MP, Rizzo AA, Sagaspe P, et al. Virtual remediation versus methylphenidate to improve distractibility in children with ADHD: A controlled randomized clinical trial study. J Atten Disord 2020 Jan 22;24(2):326-335. [doi: 10.1177/1087054718759751] [Medline: 29562853]

14. Weerdmeester J, Cima M, Granic I, Hashemian Y, Gotsis M. A feasibility study on the effectiveness of a full-body videogame intervention for decreasing attention deficit hyperactivity disorder symptoms. Games Health J 2016 Aug;5(4):258-269. [doi: $10.1089 / \mathrm{g} 4 \mathrm{~h} .2015 .0103]$ [Medline: 27304677]

15. Bul KC, Franken IH, Van der Oord S, Kato PM, Danckaerts M, Vreeke LJ, et al. Development and user satisfaction of "Plan-It Commander," a serious game for children with ADHD. Games Health J 2015 Dec;4(6):502-512. [doi: 10.1089/g4h.2015.0021] [Medline: 26325247]

16. Bul KCM, Kato PM, Van der Oord S, Danckaerts M, Vreeke LJ, Willems A, et al. Behavioral outcome effects of serious gaming as an adjunct to treatment for children with attention-deficit/hyperactivity disorder: A randomized controlled trial. J Med Internet Res 2016 Feb 16;18(2):e26 [FREE Full text] [doi: 10.2196/jmir.5173] [Medline: 26883052]

17. Jaklevic MC. Watch your medicine: Video game therapy for children with ADHD. JAMA 2020 Jul 21;324(3):224. [doi: 10.1001/jama.2020.11924] [Medline: 32692373]

18. Menendez-García A, Jiménez-Arroyo A, Rodrigo-Yanguas M, Marin-Vila M, Sánchez-Sánchez F, Roman-Riechmann E, et al. Internet, video game and mobile phone addiction in children and adolescents diagnosed with ADHD: a case-control study. Adicciones 2020 Dec 04:1469 [FREE Full text] [doi: 10.20882/adicciones. 1469] [Medline: $\underline{33338245]}$

19. Takgbajouah M, Buscemi J. Applying the developmental model of use disorders to hedonic hunger: a narrative review. $\mathbf{J}$ Addict Dis. Epub ahead of print 2021 May 18. [doi: 10.1080/10550887.2021.1926881] [Medline: 34002675]

20. Georgsdottir MT, Sigurdardottir S, Gunnthorsdottir H. "This Is the Result of Something Else": Experiences of men that abused drugs and had experienced childhood trauma. Am J Mens Health 2021 Apr 21;15(2):15579883211009348 [FREE Full text] [doi: 10.1177/15579883211009348] [Medline: 33880945]

21. Mathews CL, Morrell HER, Molle JE. Video game addiction, ADHD symptomatology, and video game reinforcement. Am J Drug Alcohol Abuse 2019 Jun 06;45(1):67-76. [doi: 10.1080/00952990.2018.1472269] [Medline: 29874473]

22. Rosholm M, Mikkelsen MB, Gumede K. Your move: The effect of chess on mathematics test scores. PLoS One 2017 May 11;12(5):e0177257. [doi: 10.1371/journal.pone.0177257] [Medline: 28494023]

23. Rabipour S, Raz A. Training the brain: fact and fad in cognitive and behavioral remediation. Brain Cogn 2012 Jul;79(2):159-179. [doi: 10.1016/j.bandc.2012.02.006] [Medline: 22463872]

24. Kollins SH, DeLoss DJ, Cañadas E, Lutz J, Findling RL, Keefe RSE, et al. A novel digital intervention for actively reducing severity of paediatric ADHD (STARS-ADHD): a randomised controlled trial. Lancet Digit Health 2020 Apr;2(4):e168-e178 [FREE Full text] [doi: 10.1016/S2589-7500(20)30017-0] [Medline: 33334505]

25. Flynn RM, Colón-Acosta N, Zhou J, Bower J. A game-based repeated assessment for cognitive monitoring: Initial usability and adherence study in a summer camp setting. J Autism Dev Disord 2019 May 17;49(5):2003-2014. [doi: 10.1007/s10803-019-03881-w] [Medline: 30656527]

26. Lange B, Flynn S, Rizzo A. Initial usability assessment of off-the-shelf video game consoles for clinical game-based motor rehabilitation. Phys Ther Rev 2013 Jul 19;14(5):355-363. [doi: 10.1179/108331909X12488667117258]

27. Bul KCM, Doove LL, Franken IHA, Oord SVD, Kato PM, Maras A. A serious game for children with Attention Deficit Hyperactivity Disorder: Who benefits the most? PLoS One 2018 Mar 15;13(3):e0193681. [doi: 10.1371/journal.pone.0193681] [Medline: 29543891]

28. Rodrigo-Yanguas M, Martin-Moratinos M, Gonzalez-Tardon C, Blasco-Fontecilla H. Virtual reality and chess. A video game for cognitive training in patients with ADHD. In: CEUR Workshop Proc. 2020 Presented at: VI Congreso de la Sociedad Española para las Ciencias del Videojuego; October 7-8, 2020; Madrid, Spain p. 205-215 URL: http://ceur-ws. org/Vol-2719/paper20.pdf

29. Baranowski T. Descriptions for articles introducing a new game for health. Games Health J 2014 Apr;3(2):55-56. [doi: 10.1089/g4h.2014.0008] [Medline: 26196042]

30. Sonuga-Barke EJ. The dual pathway model of AD/HD: an elaboration of neuro-developmental characteristics. Neurosci Biobehav Rev 2003 Nov;27(7):593-604. [doi: 10.1016/j.neubiorev.2003.08.005] [Medline: 14624804]

31. Bronowski J. Human and Animal Language. In: A Sense of the Future: Essays in Natural Philosophy. Cambridge, MA: The MIT Press; Sep 1977:104-131.

32. Fuster JM. The Prefrontal Cortex. New York: Raven Press; 1980.

33. Brown TE. ADD/ADHD and impaired executive function in clinical practice. Curr Psychiatry Rep 2008 Oct 17;10(5):407-411. [doi: 10.1007/s11920-008-0065-7] [Medline: 18803914]

34. Fullerton T. Game Design Workshop: A Playcentric Approach to Creating Innovative Games. Boca Raton, Florida: CRC Press; 2018.

35. Bergeron B. Developing Serious Games. Hingham, United States: Cengage Learning, Inc; 2006. 
36. Wang R, DeMaria S, Goldberg A, Katz D. A systematic review of serious games in training health care professionals. Simul Healthc 2016 Feb;11(1):41-51. [doi: 10.1097/SIH.0000000000000118] [Medline: 26536340]

37. Deterding S, Sicart M, Nacke L, O'Hara K, Dixon D. Gamification: Using game design elements in non-gaming contexts. 2011 May Presented at: CHI '11: CHI Conference on Human Factors in Computing Systems; May 7-12, 2011; Vancouver, British Columbia, Canada. [doi: 10.1145/1979742.1979575]

38. Matera M. Explore Like a PIRATE: Gamification and Game-Inspired Course Design to Engage, Enrich and Elevate Your Learners. San Diego, California: Dave Burgess Consulting, Incorporated; 2015.

39. Cognitive training tool for ADHD patients. Google Forms. URL: https://docs.google.com/forms/d/ 1XfYLgxtZjYzSQa3x2phVPQp07pNI LUHEfbDHYLbvOg/viewform?edit requested=true\#responses [accessed 2021-08-06]

40. Anguera JA, Brandes-Aitken AN, Rolle CE, Skinner SN, Desai SS, Bower JD, et al. Characterizing cognitive control abilities in children with 16p11.2 deletion using adaptive 'video game' technology: a pilot study. Transl Psychiatry 2016 Sep 20;6(9):e893-e893 [FREE Full text] [doi: 10.1038/tp.2016.178] [Medline: 27648915]

41. Fontecilla HMB. The Secret Trail of Moon (serious videogame) and chess on ADHD: a clinal trial. ClinicalTrials.gov. URL: https://clinicaltrials.gov/ct2/show/NCT04355065 [accessed 2021-08-06]

42. Rodrigo-Yanguas M, Martin-Moratinos M, Menendez-Garcia A, Gonzalez-Tardon C, Sanchez-Sanchez F, Royuela A, et al. A virtual reality serious videogame versus online chess augmentation in patients with attention deficit hyperactivity disorder: A randomized clinical trial. Games Health J 2021 Aug;10(4):283-292. [doi: 10.1089/g4h.2021.0073] [Medline: $\underline{34370610]}$

43. Información importante sobre salud y seguridad. PlayStation. URL: https://legaldoc.dl.playstation.net/ps3-eula/psn/e/ e health es.html [accessed 2021-08-06]

44. Roettl J, Terlutter R. The same video game in $2 \mathrm{D}, 3 \mathrm{D}$ or virtual reality - How does technology impact game evaluation and brand placements? PLoS One 2018 Jul 20;13(7):e0200724. [doi: 10.1371/journal.pone.0200724] [Medline: 30028839]

45. Merhi O, Faugloire E, Flanagan M, Stoffregen TA. Motion sickness, console video games, and head-mounted displays. Hum Factors 2007 Oct;49(5):920-934. [doi: 10.1518/001872007X230262] [Medline: 17915607]

46. Jones T, Moore T, Choo J. The impact of virtual reality on chronic pain. PLoS One 2016 Dec 20;11(12):e0167523. [doi: 10.1371/journal.pone.0167523] [Medline: 27997539]

47. Lewis JR. IBM computer usability satisfaction questionnaires: Psychometric evaluation and instructions for use. Int J Hum Comput Interact 1995 Jan;7(1):57-78. [doi: 10.1080/10447319509526110]

48. Botella C, Quero S, Baños RM, Perpiñá C, García Palacios A, Riva G. Virtual reality and psychotherapy. Stud Health Technol Inform 2004;99:37-54. [Medline: 15295145]

49. Nigg JT, Casey BJ. An integrative theory of attention-deficit/ hyperactivity disorder based on the cognitive and affective neurosciences. Dev Psychopathol 2005;17(3):785-806. [doi: 10.1017/S0954579405050376] [Medline: 16262992]

50. Gamberini L, Barresi G, Majer A, Scarpetta F. A game a day keeps the doctor away: A short review of computer games in mental healthcare. J Cyber Ther Rehabil 2008;1(2):127-145 [FREE Full text]

51. Botella C, Serrano B, Baños RM, Garcia-Palacios A. Virtual reality exposure-based therapy for the treatment of post-traumatic stress disorder: a review of its efficacy, the adequacy of the treatment protocol, and its acceptability. Neuropsychiatr Dis Treat 2015;11:2533-2545 [FREE Full text] [doi: 10.2147/NDT.S89542] [Medline: 26491332]

52. Botella C, Fernández-Álvarez J, Guillén V, García-Palacios A, Baños R. Recent progress in virtual reality exposure therapy for phobias: A systematic review. Curr Psychiatry Rep 2017 Jul 24;19(7):42. [doi: 10.1007/s11920-017-0788-4] [Medline: 28540594]

53. Rohani DA, Sorensen HBD, Puthusserypady S. Brain-computer interface using P300 and virtual reality: A gaming approach for treating ADHD. 2014 Presented at: 2014 36th Annual International Conference of the IEEE Engineering in Medicine and Biology Society; August 26-30, 2014; Chicago, Illinois, USA. [doi: 10.1109/embc.2014.6944403]

54. Friehs MA, Dechant M, Vedress S, Frings C, Mandryk RL. Effective gamification of the stop-signal task: Two controlled laboratory experiments. JMIR Serious Games 2020 Sep 08;8(3):e17810 [FREE Full text] [doi: 10.2196/17810] [Medline: 32897233]

55. Peijnenborgh JC, Hurks PP, Aldenkamp AP, van der Spek ED, Rauterberg G, Vles JS, et al. A study on the validity of a computer-based game to assess cognitive processes, reward mechanisms, and time perception in children aged 4-8 years. JMIR Serious Games 2016 Sep 22;4(2):e15 [FREE Full text] [doi: 10.2196/games.5997] [Medline: 27658428]

56. Delgado-Gómez D, Sújar A, Ardoy-Cuadros J, Bejarano-Gómez A, Aguado D, Miguelez-Fernandez C, et al. Objective assessment of attention-deficit hyperactivity disorder (ADHD) using an infinite runner-based computer game: A pilot study. Brain Sci 2020 Oct 09;10(10):716 [FREE Full text] [doi: 10.3390/brainsci10100716] [Medline: 33050130]

57. Duncan LR, Hieftje KD, Culyba S, Fiellin LE. Game playbooks: tools to guide multidisciplinary teams in developing videogame-based behavior change interventions. Transl Behav Med 2014 Mar 4;4(1):108-116 [FREE Full text] [doi: 10.1007/s13142-013-0246-8] [Medline: 24653781]

58. Instituto de Salud Carlos III. Instituto de Salud Carlos III. URL: https://www.isciii.es [accessed 2021-08-06]

59. Especialistas en tratamientos de salud mental. Ita Salud Mental. URL: https://itasaludmental.com/ [accessed 2021-08-12] 


\section{Abbreviations}

ADHD: attention-deficit/hyperactivity disorder

RCT: randomized controlled clinical trial

TSTM: The Secret Trail of Moon

VR: virtual reality

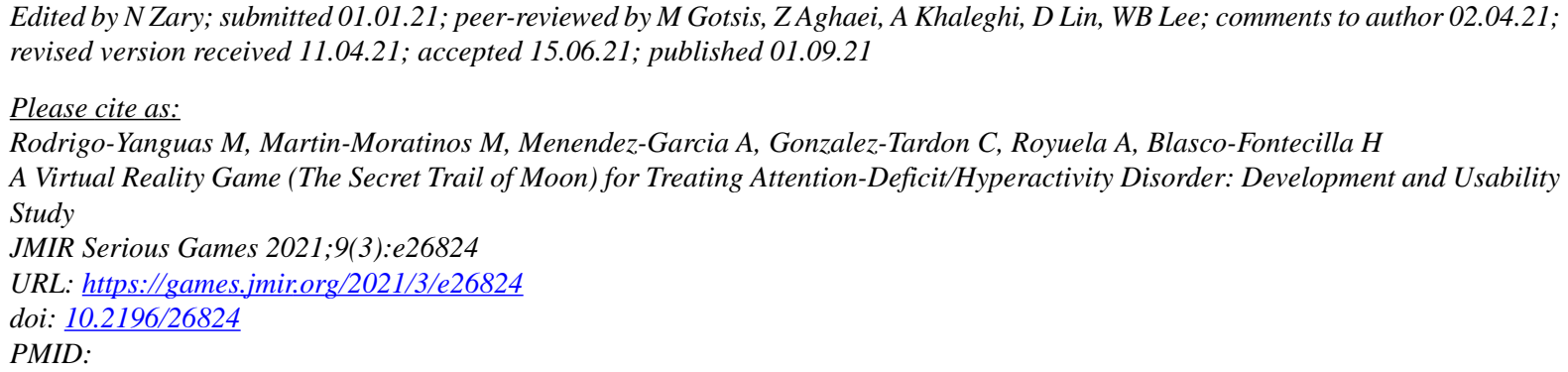

CMaria Rodrigo-Yanguas, Marina Martin-Moratinos, Angela Menendez-Garcia, Carlos Gonzalez-Tardon, Ana Royuela, Hilario Blasco-Fontecilla. Originally published in JMIR Serious Games (https://games.jmir.org), 01.09.2021. This is an open-access article distributed under the terms of the Creative Commons Attribution License (https://creativecommons.org/licenses/by/4.0/), which permits unrestricted use, distribution, and reproduction in any medium, provided the original work, first published in JMIR Serious Games, is properly cited. The complete bibliographic information, a link to the original publication on https://games.jmir.org, as well as this copyright and license information must be included. 